\title{
School-oriented mimicry, a new type of mimicry in fishes
}

\author{
Jacob Dafni and Ariel Diamant
}

The Hebrew University of Jerusalem, H. Steinitz Marine Biology Laboratory, P.O. Box 469, Eilat 88103, Israel

\begin{abstract}
The venomous Red Sea blenny Meiacanthus nigrolineatus is avoided by predatory reef fishes and is mimicked by other blenniid species. $M$. nigrolineatus juveniles $(<20 \mathrm{~mm})$ possess a distinct colour pattern - dark stripes and a basicaudal blotch - which is different from that of adults and closely resembles the colour patterns of various cardinal fish species (Apogonidae), among whose shools it is frequently found. It is suggested that solitary fish species may mimic schooling species and gain protection by mingling into their schools or aggregations. Some hitherto unclassified cases of mimicry are discussed and included in a new type of mimicry: school-oriented mimicry.
\end{abstract}

\section{INTRODUCTION}

Mimicry among fishes comprises, according to Wickler (1968), 3 main categories: Batesian mimicry, in which a harmless palatable mimic adopts the typical coloration and pattern of an unpalatable model; Müllerian mimicry, where several unpalatable species share similar colour patterns, thus enhancing their deterrent warning effects; and Aggressive mimicry, whereby predatory fishes - assuming the colour, shape and patterns of 'harmless' species - gain easier access to their potential prey. Numerous cases of each category have been reported in reef fishes (Wickler, 1961; Springer and Smith-Vaniz, 1972; Russell et al., 1976; Moyer, 1977; Ormond, 1980).

Fish schooling, according to some authors, is believed to enhance survival of the individual (EiblEibesfeldt, 1962; Shaw, 1978; Partridge, 1982). Occasionally, fishes of different species which share similar colour patterns aggregate and form mixed schools (Magnus, 1967; Ehrlich and Ehrlich, 1972; Robertson et al., 1976; Itzkowitz, 1977; Randall and Guézé, 1980). The advantage of being in a school may cause solitary fish species to seek refuge from predators by blending into such aggregations.

The venomous blenny Meiacanthus nigrolineatus Smith-Vaniz 1969, is a small planktivorous fish endemic to the Red Sea and equipped with long canines and active buccal poison glands (Fishelson, 1974). It inhabits the undercuts of ledges and crevices of shallow-water coral reefs; its behaviour and larval development were described by Fishelson (1975, 1976). As demonstrated by Springer and Smith-Vaniz (1972), this fish is involved in a mimetic complex, acting as the model in a Batesian mimetic association with the blenny Ecsenius gravieri (Pelegrin), a harmless fish, and in Müllerian and aggressive mimetic association with the sabretoothed blenny Plagiotremus townsendi (Regan).

Similar mimetic complexes involving other blennies of the genus Meiacanthus were reported by Losey (1972), Springer and Smith-Vaniz (1972), and Russell et al. (1976) and summarized by Smith-Vaniz (1976). In all these cases Meiacanthus spp. act as the models.

In the present study, an additional form of mimicry is introduced, termed by us school-oriented mimicry, in which a solitary species, at some stage in its life history, assumes the coloration pattern of one or more gregarious species, and blends into their aggregations. This type of mimicry differs from aggressive mimicry by its protective nature. School-oriented mimicry offers increased protection to the mimic, rendering it less vulnerable, rather than enhancing access to elusive food items, as does aggressive mimicry. Juveniles of Meiacanthus nigrolineatus are involved in this type of mimicry, acting as mimics of young cardinal fishes.

\section{METHODS}

Observations on mimic and models - cardinal fishes (Apogonidae) - were carried out in the northern part of 
the Gulf of Eilat (Gulf of Aqaba) from June to September 1983, by skin and SCUBA diving to a depth of $15 \mathrm{~m}$. Observations made in previous years in southern parts of the Gulf were included as well. Fish were caught using the anesthetic Quinaldine (Sigma Corp. no. Q2125) and hand nets. Underwater photographs were made with a Nikonos II and close-up lens. Living fish were held in captivity at ambient temperatures (23 to $25^{\circ} \mathrm{C}$ ) in flow-through tanks.

In a feeding experiment, young lionfish Pterois volitans (L.) of a total length (TL) of 12 to $18 \mathrm{~cm}$, were offered daily (at $2 \mathrm{pm}$ ) 3 Meiacanthus nigrolineatus juveniles (up to $18 \mathrm{~mm} \mathrm{TL}$ ) and 3 cardinal fishes (mainly Apogon cyanosoma Bleeker) (15 to $25 \mathrm{~mm} \mathrm{TL}$ ). Each experiment lasted 5 to $7 \mathrm{~d}$, and the number of ingested prey individuals was recorded. Predator behaviour was followed for $1 \mathrm{~h}$ after introduction of prey fish. A new freshly caught lionfish was introduced for each experiment.

\section{RESULTS}

Recruitment of young cardinal fishes (Apogonidae) of various species occurs in the Gulf of Eilat during summer. The juveniles aggregate in small schools and shelter among the spines of the long-spined sea urchin Diadema setosum (Leske) (Abel, 1960). The cardinal fishes share a common colour pattern of longitudinal stripes, black (Apogon angustatus Smith and Redcliffe, Cheilodipterus quinquelineatus [Cuvier and Valenciennes], C. bipunctatus [Lachner]) or brown-yellow (Apogon cyanosoma) on a pale background. The same pattern is shown by juvenile C. lachneri Klausewitz, which at this life stage are practically indistinguishable from other species of Cheilodipterus (Magnus, 1967). This striped pattern is reinforced in $A$. cyanosoma juveniles by concentrations of pigment along the upper part of the spinal cord, which are plainly visible through the largely transparent body. Most of these cardinal fishes possess a dark blotch of variable size on the caudal peduncle, which stands out due to a yellow or orange background. While $A$. cyanosoma possesses an orange peduncle without a dark blotch, some of the other cardinal fishes show the dark spot without the coloured background (e.g. Archamia fucata [Cantor], A. lineolata [Ehrenberg]). Cardinal fish juveniles associate in monotypic or mixed aggregations, in which $A$. cyanosoma and $A$. angustatus are predominantly found. Adult $C$. bipunctatus and $C$. quinquelineatus also occur in mixed schools of the 2 species. C. lachneri may be seen either in these mixed schools or singly.

Juveniles of Meiacanthus nigrolineatus, greater than $10 \mathrm{~mm} \mathrm{TL}$, are found solitarily or in groups of 2 to 3 individuals within schools of 10 to 100 cardinal fish (Fig. 1). They are almost indistinguishable from the cardinal fish Cheilodipterus spp. at this size and look extremely similar to other striped cardinal fishes as well (Fig. 2). In juvenile M. nigrolineatus 3 dark stripes extend laterally from the head along the body and fade at the caudal base. The uppermost stripe runs along the dorsal fin base, the central stripe marks the midline, covering the eye, and the ventral stripe runs parallel beneath the eye. The caudal peduncle is marked by a black spot, surrounded by a bright yellow margin. The dorsal fin is continuous and bears a dark ocellus anteriorly. This colour pattern agrees with Fishelson's (1976) description. At a later stage (>14 mm) a bluish tinge appears at the anterior part of trunk and head.

This juvenile colour pattern persists until the fish attains 25 to $30 \mathrm{~mm}$ TL. The anterior part of the body then turns blue-grey and all but the uppermost stripe gradually fade and vanish. In specimens over $20 \mathrm{~mm}$ the tail darkens at its lower and upper margins. The adult colour pattern, described by Smith-Vaniz (1969) and Fishelson (1975), is shown by all specimens $>30 \mathrm{~mm}$ TL.

The association with cardinal fishes gradually decreases as the blenny juveniles grow, consequently dispersing or gathering in groups of 3 to 6 individuals of various sizes, which may even include an adult. At this stage they begin to swim into open water, up to a distance of $1 \mathrm{~m}$ from their shelters. When disturbed, they seek refuge in the coral crevices or among the spines of Diadema setosum. In captivity, they cling to the bottom or to the corner of an aquarium.

The shared colour patterns of mixed schooling cardinal fishes is a clear case of 'arithmetic mimicry', classified as 'synergic inviting mimicry' by Vane-Wright (1976), who also discussed its advantages. The generality of the cardinal fish shared pattern phenomenon is suggested by its wide distribution in other parts of the Indo-Pacific region. It is further exhibited by Apogon endekataenia, A. nigrofasciatus, A. novemfasciatus, A. robustus, Archamia buruensis and Cheilodipterus isostigma.

Juveniles of Meiacanthus nigrolineatus, sharing this common colour pattern in the presence of the cardinal fish, present another case of mimicry for the following reasons:

(1) Cardinal fishes, harmless and prone to predation by many reef carnivores, represent poor models for both Batesian and Müllerian mimicry.

(2) Venomous blenny juveniles, although possessing venomous fangs, are not likely to be considered as a Batesian model since they are limited both temporally (displaying the juvenile pattern only during a short growth season) and geographically (M. nigrolineatus 
Fig. 1. Underwater photograph of a $15 \mathrm{~mm}$ Meiacanthus nigrolineatus (at the upper left corner) among Apogon cyanosoma (Eilat coral reef, $8 \mathrm{~m}$ )

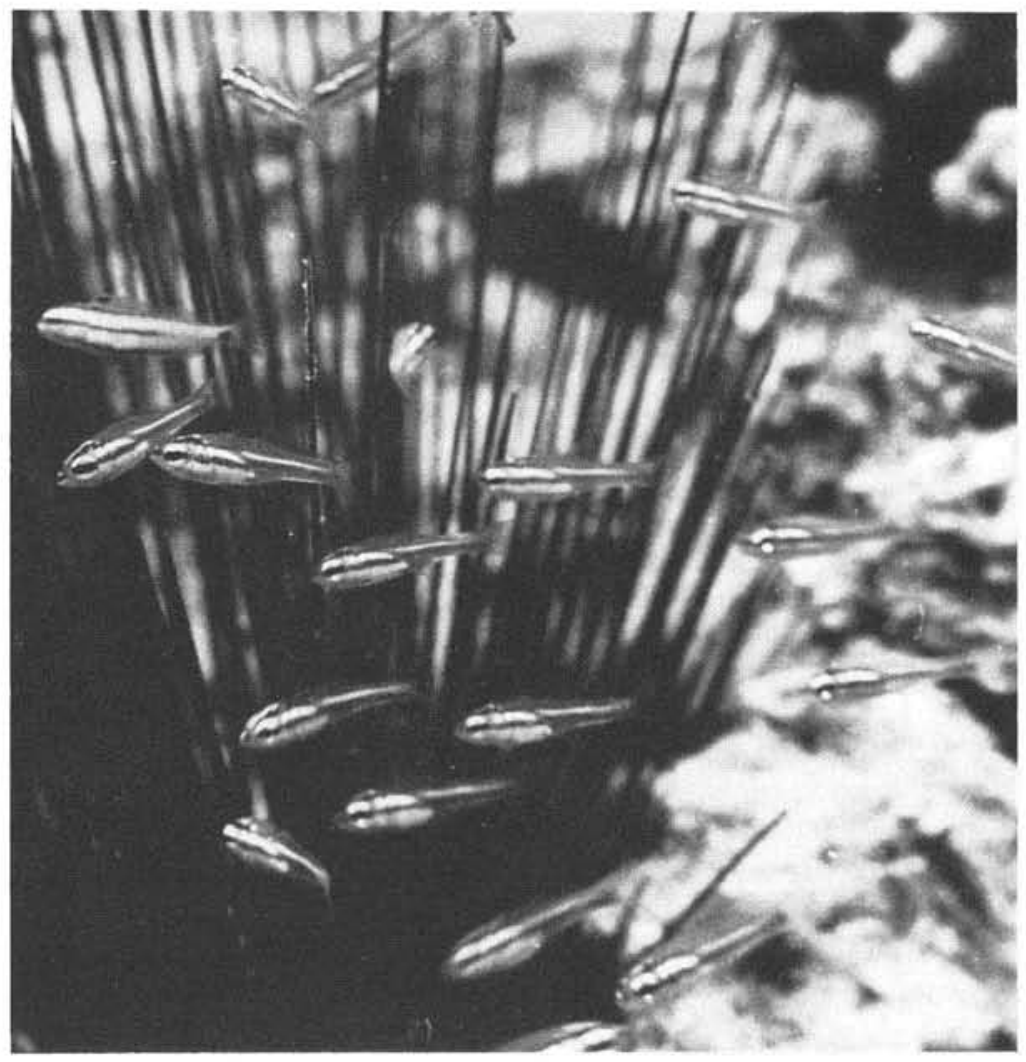

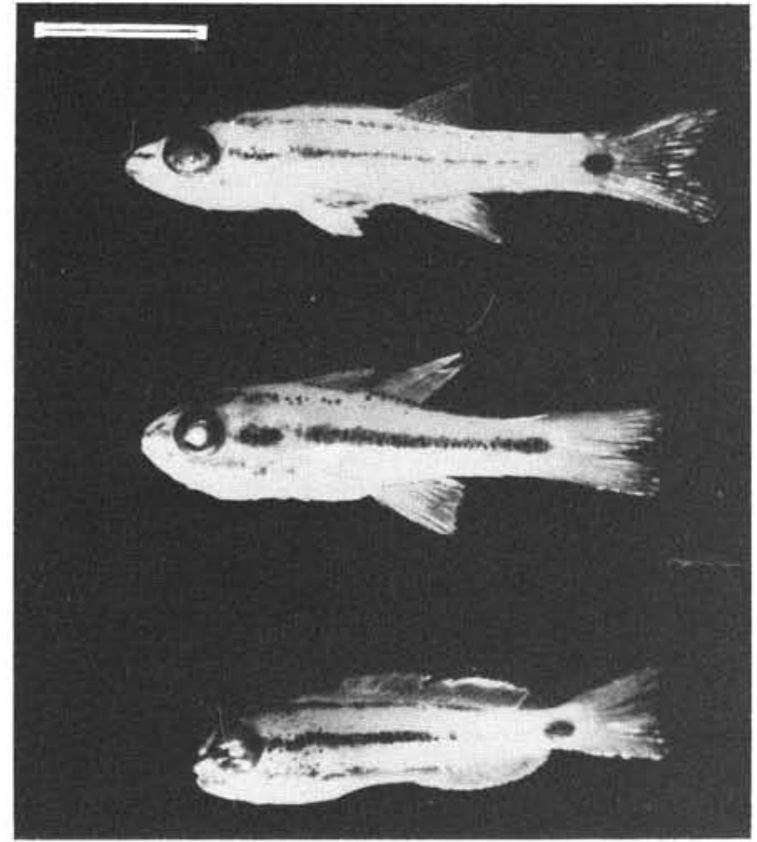

Fig. 2. Comparison between the models - Cheilodipterus bipunctatus (top), Apogon angustatus (middle) and the mimic M. nigrolineatus. Bar is $5 \mathrm{~mm}$

is known only from the Red Sea, whereas most Red Sea cardinal fishes have an Indo-Pacific range).

(3) Many cardinal fishes display the common colour pattern up to their maximal size $(20 \mathrm{~cm}$ in Cheilodipterus spp.), whereas in the venomous blenny it changes at a size of $<3 \mathrm{~cm}$.

(4) Aggressive mimicry in which the venomous blenny acts as mimic could be considered, if the mimic fed on larger prey than the model, a criterion used by Randall and Randall (1960) and Starck (1969). The gut content of 5 venomous blennies (10 to $20 \mathrm{~mm}$ TL) caught at noon or in the late afternoon, consisted mainly of planktonic copepods of an average size of $500 \mu \mathrm{m}$, and occasional ostracods, fish-eggs and filamentous algae. Stomachs of cardinal fishes, Archamia cyanosoma and C. bipunctatus ( 8 to $13 \mathrm{~mm}$ TL), contained copepods somewhat larger than found in the blennies, cypris larvae of cirripeds and other unidentified arthropods. This analysis confirms earlier observations by Fishelson (1976). Both blennies and cardinal fishes, therefore, feed on similar-sized mesoplanktonic crustaceans, while adult cardinal fishes, prey on yet larger organisms (Hiatt and Strasburg, 1960; Vivien, 1975).

The apparent benefit accrued to solitary or dispersed fish which join other species' aggregations, has been discussed by Randall and Randall (1960), Alevizon (1976), Robertson et al. (1976) and Itzkowitz (1977). Starck (1969) identified a blenny, Ecsenius (Anthiiblennius) midas, that mimics the colour pattern and behaviour of Anthias squamipinnis (Anthiidae), 
among whose aggregations it was observed, but the author found no form of mimicry applicable.

We suggest that cases of mimicry of solitary or highly dispersed species, which assume a colour pattern displayed by gregarious species - and the visual pattern is apparently used as an anti-predatory device - should be recognised as a distinct form of mimicry, namely school-oriented mimicry. This type of mimicry has a certain similarity to Batesian mimicry, since the mimics take advantage of the model coloration and schooling habits, to become less prone to predation. However, it is clearly not Batesian mimicry as presently defined.

In this case, the mimic may also contribute to the protective value of the model's coloration. Being more agile and also harmful due to the buccal poison glands, it can produce negative effects upon the common predator. Feeding experiments with small lionfish indicate that avoidance of juvenile blennies is acquired only following several trials. This suggests that the venomous glands are functional at this early stage, in accordance with earlier observations (Fishelson, 1976). Thus, a very loose form of Müllerian mimicry is also conceivable. The most important feature of schooloriented mimicry, however, is that it is based on the gregarious nature of the model.

This form of mimicry also applies to Ecsenius midas' affinity to schooling Anthias squamipinnis, where the protection obtained by blending into the model's school is apparent. School-oriented mimicry was observed between pomacentrid fishes and 3 different anthiine fishes, at Fanning Island, Line Islands (McCosker and Randall, MS). Formerly described cases of aggressive mimicry, such as Lutjanus bohar juveniles mimicking Chromis spp. (Russell et al., 1976; Moyer, 1977), may also be reclassified as schooloriented mimicry, if shown that the principle advantage derived by the mimic is protection against predation, while feeding in midwater.

The juvenile pattern of at least one additional Meiacanthus species, $M$. mossambicus Smith, is very similar to that of juvenile $M$. nigrolineatus. Thus, the basicaudal spot and striped colour patterns are possibly characteristic of juveniles of this genus (W. F. Smith-Vaniz, pers. comm.). This pattern could have at least in the latter species, facilitated school-oriented mimicry with the cardinal fish. It would be interesting to find out whether juveniles of other species of Meiacanthus, in other parts of the Indo-Pacific region, show similar relations with cardinal fishes.

The results of our feeding experiments are shown in Fig. 3. During the first day, the predators devoured both model and mimic in similar numbers. Gradually, the lionfish's preference shifted to cardinal fish and it began to avoid its mimic. It was often observed that the

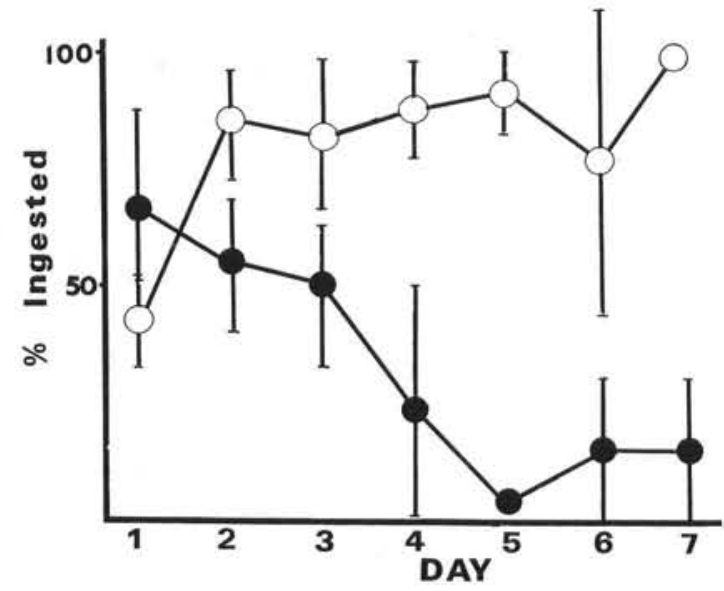

Fig. 3. Percentage (mean \pm SE) of prey ingested and eaten by the lionfish Pterois volitans in the $7 \mathrm{~d}$ feeding experiments: ○ Apogon cyanosoma; $\bullet$ Meiacanthus nigrolineatus

predator, after ingesting a blenny, ejected its prey within 1 to $2 \mathrm{~min}$, while flaring its gills and protruding the mouth. On one occasion the lionfish ingested one of each prey species shortly one after the other. It ejected both, only to re-ingest the cardinal fish immediately. The rejected mimic swam away unharmed. On the following days the predator ate the cardinal fishes immediately upon introduction, whereas the mimic, if at all, was usually taken during late afternoon or at night. On several occasions, the lionfish, possibly due to a painful experience with the blenny, avoided both mimic and model for several days.

\section{DISCUSSION}

The term 'mimicry' includes many cases of mutual resemblance in patterns of colour and behaviour between living organisms. Some examples fall into the strict definition of the known forms of mimicry, whereas others are subject to considerable dispute (Wickler, 1965, 1968). In Batesian mimicry, the model is avoided by predators due to various repugnant effects (noxious taste, poison, spines, etc.) and its aposematic colour pattern is used to advertise them. The mimic is palatable but is avoided, owing to its resemblance to the unpalatable model.

The cardinal fishes in our study are palatable to predatory fishes. They do not possess any known active defense and are preyed upon by various carnivorous reef fishes (Hiatt and Strasburg, 1960; Randall and Brock, 1960). Hence, a Batesian mimicry, with cardinal fishes as the model is unlikely.

The colour patterns of various cardinal fishes are presumed to be aimed at discouraging predators in several ways. According to Barlow (1972), longitudinal 
stripes have a confusing effect on predators. The basicaudal spot may divert their attention from the head and the usually camouflaged eye (Wickler, 1968). These shared patterns cannot be termed Müllerian mimicry in the strict sense, since Müllerian mimics are assumed to be unpalatable and deter predators visually. Müllerian mimicry is further ruled out as the apogonid colour pattern is conceivably due to common ancestry rather than to convergent origin (Wickler, 1965).

Why does a species that is highly immune in the adult stage possess a totally different colour pattern as juvenile? Being more vulnerable to predation, at least during the first encounter with a predator (as shown in our experiment), adoption of the adult colour pattern by the less venomous juveniles would, conceivably, reduce its warning effectiveness. School-oriented mimicry may thus serve as an attractive alternative which would enhance species survival. Cases of mutual resemblance, in which both participating species are highly gregarious (Shaw, 1978), remain unexplained. They may, however, be regarded as Batesian mimicry, if one species is less desired by the predators (Randall and Randall, 1960; Randall and Guézé, 1980); or as school-oriented mimicry, if both are equally vulnerable, and rely on mixed schooling as a protective strategy.

School-oriented mimicry can be also classified as 'synergic inviting mimicry' (see Vane-Wright, 1976). According to this scheme, the mimic contributes to the model's survival by increasing the numbers sharing the same pattern. In this particular case, 'arithmetic contribution' is obviously not the case, as the venomous Meiacanthus nigrolineatus is a solitary species. It could, however, contribute to the association by its deterrent venomous effect.

Acknowledgements. We acknowledge the help by our colleagues at the H. Steinitz Marine Biology Laboratory, and the Hebrew University of Jerusalem. Special thanks are due to L. Fishelson, J. E. McCosker, A. Myrberg Jr., J. E. Randall, W. F. Smith-Vaniz and V. G. Springer for critically reading the manuscript; their considerable contribution and important suggestions are greatly appreciated.

\section{LITERATURE CITED}

Abel, E. (1960). Fische zwischen Seeigel-Stacheln. Natur Volk 90 (2): 33-77

Alevizon, W. S. (1976). Mixed schooling and its possible significance in a tropical western Atlantic parrotfish and surgeonfish. Copeia 4: 769-779

Barlow, G. W. (1972). The attitude of fish eye-lines in relation to body shape and to stripes and bars. Copeia 1: 4-12

Ehrlich, P., Ehrlich, A. (1972). Coevolution: Heterotypic schooling in Caribbean reef fishes. Am. Nat. 107 (953): $157-160$
Eibl-Eibesfeldt, I. (1962). Freiwasserbeobachtungen zur Deutung des Schwarmverhaltens verschiedener Fische. $\mathrm{Z}$. Tierpsych. 9 (2): 165-182

Fishelson, L. (1974). Histology and ultrastructure of the recently found buccal toxic gland in the fish Meiacanthus nigrolineatus. Copeia 2: 386-392

Fishelson, L. (1975). Observations on behaviour of the fish Meiacanthus nigrolineatus Smith-Vaniz (Bleniidae) in nature (Red Sea) and in captivity. Austr. J. mar. Freshwat. Res. 26: 329-341

Fishelson, L. (1976). Spawning and larval development of the blennid fish Meiacanthus nigrolineatus from the Red Sea. Copeia 4: 798-800

Hiatt, R. W., Strasburg, D. W. (1960). Ecological relationships of the fish fauna on coral reefs of the Marshall Islands. Ecol. Monogr. 30: 65-127

Itzkowitz, M. (1977). Social dynamics of mixed-species groups of Jamaican reef fishes. Behav. Ecol. Sociobiol. 2: 361-384

Losey, G. S. (1972). Predation protection in the poison-fang blenny Meiacanthus atrodorsalis, and its mimics, Ecsenius bicolor and Runula laudandus (Blenniidae). Pacif. Sci. 26: 127-139

Magnus, D. B. E. (1967). Ecological and ethological studies and experiments on the echinoderms of the Red Sea. Stud. trop. Oceanogr. 5: 635-664

Moyer, J. T. (1977). Aggressive mimicry between juveniles of the snapper Lutjanus bohar and species of the damselfish genus Chromis from Japan. Jap. J. Ichthyol. 27: 218-222

Ormond, R. F. G. (1980). Aggressive mimicry and other interspecific feeding associations among Red Sea coral reef predators. J. Zool., Lond. 191: 247-262

Partridge, B. (1982). The structure and function of fish schools. Scient. Am. 246: 114-121

Randall, J. E., Brock, V. E. (1960). Observations on the ecology of Epinepheline and Lutjanid fishes of the Society Islands with emphasis on food habits. Trans. Am. Fish. Soc. 89 (1): 9-16

Randall, J. E., Guézé, P. (1980). The goatfish Mulloidichthys mimicus n. sp. (Pisces, Mullidae) from Oceania, a mimic of the snapper Lutjanus kasmira (Pisces, Lutjanidae). Bull. Mus. natn. Hist., Paris, 4e ser., 2 section A, 2: 603-609

Randall, J. E., Randall, H. A. (1960). Examples of mimicry and protective resemblance in tropical marine fish. Bull. mar. Sci. Gulf Caribb. 10: 444-480

Robertson, D. R., Sweatman, H. P. A., Fletcher, E. A., Cleland, M. G. (1976). Schooling as a mechanism for circumventing the territoriality of competitors. Ecology 57: 1208-1220

Russell, B. C., Allen, G. R., Lubbock, H. R. (1976). New cases of mimicry in marine fishes. J. Zool., Lond. 180: 407-423

Shaw, E. (1978). Schooling fishes. Am. Sci. 66 (2): 166-175

Smith-Vaniz, W. F. (1969). A new species of Meiacanthus (Pisces; Blenniidae; Nemophidinae) from the Red Sea, with a review of the Indian Ocean species. Proc. biol. Soc. Wash. 82: 349-354

Smith-Vaniz, W. F. (1976). The saber-toothed blennies, tribe Nemophini (Pisces: Blenniidae). Acad. Nat. Sci. Phila. Monograph 19: 1-196

Springer, V. G., Smith-Vaniz, W. F. (1972). Mimetic relationships involving fishes of the family Blenniidae. Smithson. Instn Contr. Zool. 112: 1-36

Starck, W. A. (1969). Ecsenius (Anthiiblennius) midas, a new subgenus and species of mimic blenny from the western Indian Ocean. Notul. Nat. 419: 1-9

Vane-Wright, R. L. (1976). A unified classification of mimetic resemblances. Linn. Soc. Lond., Biol. J. 8 (1): 25-56 
Vivien, M. L. (1975). Place of apogonid fish in the food webs of a malagasy coral reef. Micronesica 11 (2): 185-198

Wickler, W. (1961). Uber das Verhalten der Blenniiden Runula und Aspidontus (Pisces, Blenniidae). Z. Tierpsych. 18: $421-440$
Wickler, W. (1965). Mimicry and the evolution of animal communication. Nature, Lond. 208 (5010): 519-521

Wickler, W. (1968). Mimicry in plants and animals. Weidenfeld \& Nicholson, London

This paper was presented by Professor L. Fishelson; it was accepted for printing on May 18, 1984 